CARRARETTO Maryse, Histoires de maïs. D'une divinité amérindienne à ses avatars transgéniques, Éditions du CTHS, Paris, 2005, 267 p., bibl., ill., photos, tabl.

\title{
Esther Katz
}

\section{(2) OpenEdition}

\section{Journals}

Édition électronique

URL : https://journals.openedition.org/jsa/3223

DOI : $10.4000 /$ jsa.3223

ISSN : 1957-7842

Éditeur

Société des américanistes

Édition imprimée

Date de publication : 1 juin 2006

ISSN : 0037-9174

Référence électronique

Esther Katz, " CARRAREtTo Maryse, Histoires de maïs. D'une divinité amérindienne à ses avatars transgéniques, Éditions du CTHS, Paris, 2005, 267 p., bibl., ill., photos, tabl. », Journal de la Société des américanistes [En ligne], 92-1 et 2 | 2006, mis en ligne le 06 avril 2007, consulté le 04 septembre 2022 URL : http://journals.openedition.org/jsa/3223 ; DOI : https://doi.org/10.4000/jsa.3223

Ce document a été généré automatiquement le 4 septembre 2022.

Tous droits réservés 


\title{
CARRARETTO Maryse, Histoires de maïs. D'une divinité amérindienne à ses avatars transgéniques, Éditions du CTHS, Paris, 2005, 267 p., bibl., ill., photos, tabl.
}

\author{
Esther Katz
}

1 Sur le continent américain, le maïs fait souvent partie du paysage. Même sans se dédier à son étude, de nombreux chercheurs américanistes ont pu observer sa culture et connaissent l'importance symbolique de cette plante pour les populations indigènes, notamment en Mésoamérique. Mais qu'en est-il en Europe? Divers ouvrages, piochant toujours dans les mêmes sources, relatent la découverte de nouvelles plantes par Christophe Colomb, dès son premier voyage à Hispaniola, la présentation qu'il en fit aux souverains espagnols et la diffusion immédiate de certaines d'entre elles, dont le maïs. Dans Histoires de maïs, Maryse Carraretto montre que le cheminement entre l'arrivée du maïs en Espagne et son adoption à travers l'Europe a été particulièrement complexe. Elle retrace avec soin cette histoire et ses diverses étapes, de l'Amérique du $\mathrm{XVI}^{\mathrm{e}}$ siècle à l'Europe d'aujourd'hui. Surtout, elle ne se contente pas seulement d'en relater les événements, mais encore elle analyse les représentations de cette plante au fil des siècles, en s'appuyant à la fois sur des documents de diverses époques et sur ses propres enquêtes ethnographiques centrées principalement dans les régions du Lauragais, près de Toulouse, et de l'Entre-Douro-e-Minho, au nord du Portugal. Le lourd appareil de notes pourrait être critiqué mais, dans le cas de cet ouvrage, il est bien utile: les nombreuses références à des archives ou à des entrevues attestent le point de vue de l'auteur sans charger le texte qui reste agréable à lire.

2 Le chapitre I renvoie aux premières rencontres entre les Européens et le maïs qui « occupait de grands espaces, du bord des Grands Lacs américains jusqu'au sud du Chili ». Les américanistes resteront bien sûr frustrés du fait que seulement une quinzaine de 
pages soient consacrées à la culture du maïs, à ses utilisations, aux croyances et aux représentations qui lui sont liées, et cela sur l'ensemble du continent. En raison de l'équilibre entre les chapitres, il aurait été mal venu d'allonger cette partie qui représente un véritable tour de force du point de vue de la synthèse et de la mise en parallèle de pratiques au sein de populations aussi différentes que les Iroquois, les Mexicas et les Incas. On peut toutefois reprocher à l'auteur d'avoir omis quelques phases du cycle agricole qui ne se limite pas aux semailles et à la récolte. Le maïs occupe-t-il vraiment un temps réduit, comme elle l'affirme? Ou serait-ce parce qu'elle n'y inclut pas la préparation du terrain, les désherbages et l'éventuel pliage de la tige?

3 À partir d'une importante documentation qui va des ouvrages de botanique du Xvi siècle aux archives locales, elle retrace ensuite le long chemin, souvent semé d'embûches, de l'intégration du maïs. Bien que son introduction en Espagne par Christophe Colomb ait été attestée, pendant près de deux siècles les naturalistes se querellent sur son origine. Sa provenance américaine, évidente pour certains, est mise en doute par d'autres ; les noms qui lui sont attribués augmentent la confusion: maïs, millet, sorgho, blé d'Inde (se référant aux Indes occidentales), d'Espagne, de Turquie (représentant à l'époque l'altérité)... Si certaines régions d'Espagne et du Portugal - ainsi que la Vénétie adoptent le maïs dès le $\mathrm{xVI}^{\mathrm{e}}$ siècle, ce processus d'adoption met entre un et deux siècles dans d'autres parties de l'Europe (sud-ouest de la France, Italie, Hongrie, Balkans). Notons qu'il en est de même pour le piment (Katz 1992). Seul le haricot semble s'être substitué rapidement et sans équivoque au dolique (Vigna unguiculata). Malgré une analyse très précise des documents historiques, Maryse Carraretto ne mentionne que les sources premières d'introduction du maïs et non celles sur plusieurs vagues en provenance de diverses parties du continent américain. Il est en effet probable que cela n'apparaisse pas dans les nombreux ouvrages et archives qu'elle a consultés. Il convient donc de signaler les résultats obtenus récemment par des généticiens qui ont travaillé en collaboration avec l'historienne Monique Chastanet (Rebourg et al. 2002) et ont mis en évidence, pour les maïs cultivés en Europe, deux souches : l'une caribéenne et l'autre nord-américaine, de l'est des États-Unis, plus adaptée aux climats tempérés. La première se retrouve dans le sud de l'Espagne, la seconde dans le nord de la zone de culture du maïs en Europe ; les maïs cultivés dans le nord-ouest de l'Espagne et dans le sud-ouest de la France sont le produit d'une hybridation de ces deux souches. Quoi qu'il en soit, le maïs n'a pas été adopté sans réticences. Classé immédiatement dans la catégorie des céréales, le maïs a été perçu comme « don de Dieu » en raison de la taille de ses épis, de ses grains et de ses extraordinaires rendements par rapport à ceux du blé, mais aussi comme « part du Diable » à cause des souffrances qu'a engendrées sa consommation : des paysans pauvres de régions entières, au régime peu varié, ont en effet contracté la pellagre car ils préféraient vendre le blé plus cher et consommer le maïs, pourtant destiné d'abord aux animaux. Chaque nouvelle phase d'introduction, celle des semences hybrides après la seconde guerre mondiale, puis des OGM à partir de la fin des années 1990, a déclenché de l'engouement, des passions et des résistances. Tout d'abord cultivé discrètement dans les jardins, lieux d'acclimatation par excellence, et échappant à la dîme, le maïs a pris place dans les champs, perpétuant l'association qu'il forme en Amérique avec le haricot. Dans les régions où elle a été initiée entre le $\mathrm{XVI}^{\mathrm{e}}$ et le $\mathrm{xVIII}{ }^{\mathrm{e}}$ siècle, sa culture est devenue tradition. Des bouillies locales de maïs, souvent encore méconnues, milhas, cruchade, gaudes, font partie de la cuisine de terroirs régionaux français ; la polenta italienne et la mamaliga roumaine sont devenues des plats nationaux. Dans ces mêmes régions d'Europe, le maïs est perçu comme anthropomorphe et 
représente la fertilité, tout comme aux Amériques. Sans que les symboles des cultures amérindiennes aient été transmis, le statut de la plante donne lieu à des réinterprétations propres - comme pour le piment (Katz 1992) - et, dans toute cette aire de l'Europe, apparaissent à peu près les mêmes représentations. Le laboureur prépare tout d'abord la terre qui servira de « berceau » au maïs, « femmes et enfants déposent les grains en terre en espérant que leur germination se fera sans qu'ils avortent" puis, au cours du désherbage, on "chausse» les pieds de maïs en relevant la terre autour des tiges afin qu'il puisse "grandir ", tout en étant protégé. Après que le pollen de l'épi mâle ait fécondé les soies des fleurs femelles, on "enlève la tête » du maïs. On le récolte ensuite entouré de ses spathes. "Les enfants transforment les épis en poupées, tandis que les plus grands - filles et garçons rassemblés à la veillée - le placent au centre de leurs jeux amoureux ». Ils « déshabillent » l'épi, lui ôtent sa « robe » ou sa « chemise » à l'aide d'un poinçon, parfois sculpté en forme de corps de femme et offert par un garçon à l'élue de son cœur; en même temps, les « effeuilleurs » blaguent autour de la panouille phallique ou du poinçon qui déflore et peuvent s'embrasser s'ils trouvent un épi rouge. Le déroulement de ces travaux n'est plus que souvenir aujourd'hui, ces manières de faire ont disparu avec la mécanisation de l'agriculture. Néanmoins, l'idée de jeux amoureux entre filles et garçons persiste dans la culture des maïs hybrides, lorsqu'il s'agit de " castrer » le maïs manuellement en sélectionnant par rangées des plantes mâles ou femelles. C'est au maïs hybride et aux OGM qu'est consacrée la dernière partie de l'ouvrage. Maryse Carraretto a passé au crible de l'enquête ethnographique les différents acteurs (agronomes, agriculteurs, administrateurs...) qui ont été confrontés à ces introductions et ont éventuellement adopté ces variétés. Après la seconde guerre mondiale, le maïs hybride, produit de technologies agronomiques développées aux États-Unis, n'a véritablement trouvé sa place en France qu'après avoir été croisé à son tour à des variétés locales. Avec la mécanisation et l'aide de techniques élaborées d'irrigation, sa culture s'est alors étendue à de plus grandes surfaces et à un plus grand nombre de régions. Le maïs OGM est encore réduit à l'état d'expérimentation, mais rien ne présage encore de l'avenir.

Histoires de maïs a l'avantage de combiner des sources et des approches diverses sur le maïs. Présentant ainsi "le tour de la question», il devient incontournable. Assez synthétique et bien équilibré, qu'il décrive l'histoire de l'adoption du maïs, les techniques ou l'imaginaire des agricultureurs et des agronomes, cet ouvrage se lit toujours comme un roman. Une lecture à recommander donc.

\section{BIBLIOGRAPHIE}

\section{KATZ Esther}

1992 « Deux solanées rouges de l'Amérique à l'Europe ", Les Cahiers d'Outre-Mer, numéro spécial Les plantes américaines à la conquête du monde, 179-180, pp. 287-302.

Rebourg Cécile, Monique chastanet, Brigitte gouesnard, Claude WelCKer, Pierre dubreull et Alain CHARCOSSET 
2003 « Maize introduction into Europe: the history reviewed in the light of molecular data ", Theoretical and Applied Genetics, 106, pp. 895-903.

\section{AUTEURS}

\section{ESTHER KATZ}

IRD/Muséum national d'histoire naturelle, Paris 